\title{
(RE)CONSTRUÇÃO DO HERÓI: O MIGRANTE NORDESTINO COMO METÁFORA DA FORMA EM ELES ERAM MUITOS CAVALOS
}

\author{
(Re)Construction of the hero: the Northeastern migrant as \\ a form metaphor in Eles eram muitos cavalos
}

Rodrigo Ennes da Cunha*

$\mathrm{N}$ o Brasil dos últimos tempos, é evidente o crescimento do número de artistas dispostos a enfrentar o desafio estético da representação da pobreza nas mais diversas searas da arte. Para tentarmos entender as razões sóciohistóricas para esse fenômeno, talvez seja necessário considerar o processo acelerado e irregular de urbanização nos grandes centros urbanos. Se, de um lado, isso certamente contribuiu para o cenário de caos social que presenciamos diariamente, de outro, forçou a aproximação entre o centro e a periferia.

Uma das conseqüências dessa aproximação foi naturalização da convivência entre as elites econômicas e culturais e a efervescência cultural dos guetos, o que, entre outros fatores, resulta, na literatura brasileira contemporânea, em diversas propostas de renovação estética no trato do tema. Uma delas, é Eles eram muitos cavalos (2002), de Luiz Ruffato.

Ruffato não veio de gueto, nem teve seu caminho iluminado pelos holofotes das elites, mas é de origem humilde: foi pipoqueiro, balconista e operário em Cataguases, interior de Minas Gerais. Já em São Paulo, torna-se jornalista conceituado na imprensa local e lança Histórias de remorsos e de rancores (1998) e (os sobreviventes) (2000). Nesses dois livros de contos, o autor retrata a vida do operariado em sua cidade natal, durante o regime militar.

Em Eles eram muitos cavalos, seu primeiro romance, o autor centra o foco na cidade de São Paulo, para escrever sobre a vida do homem comum da metrópole.

* Universidade Federal do Rio Grande do Sul 
A narrativa é dividida em 70 pequenos textos. Em alguns deles, os narradores escrutinam a vida de vendedores ambulantes, motoristas de táxi, idosos, pastores, pedintes, assaltantes que, embora vivendo em uma mesma cidade, não exercem qualquer influência direta uns sobre os outros. Isso pode até ser típico da vida da grande cidade, mas se torna peculiar quando representa uma proposta de romance, na medida em que, em nenhum momento, as histórias se cruzam.

Assim, não há um enredo como fio condutor que relacione qualquer uma das partes ou as personagens. O único vínculo entre elas parece ser o do tempo ficcional, um dia, o que permite ler este conjunto de textos como um grande retrato da diversidade na paisagem humana no cotidiano da cidade. Neste trabalho, o roteiro para essa leitura passa por dois capítulos que têm como pano de fundo a migração nordestina. Através do estudo da representação da figura do migrante, sobretudo de seu processo de adaptação a um mundo diferente ao seu de origem, tentaremos alcançar a idéia de diversidade no todo da obra.

A análise começa com algumas considerações sobre o caráter formal. A divisão da narrativa entre vários tipos de textos é o ponto de partida. A fragmentação entre as partes, às vezes, é marcada pela diferença entre os gêneros da narrativa. Os narradores formam um mosaico textual composto por cartas, orações, cardápios, previsões meteorológicas, lista de livros, anúncios de classificados, além de textos que podem funcionar como pequenos contos.

A fragmentação que é evidente entre as partes do romance também aparece em um mesmo capítulo. Como no exemplo abaixo, extraído do capítulo 6, intitulado "Mãe", que relata a viagem de ônibus de uma velha senhora na linha Garanhuns São Paulo:

...E agora? Tá perto? Paciência, vovó!, Ainda demora um pouquinho ainda, (...) Ô vovó, já tamos quase a bexiga estufada, dói a barriga, as costas, Ai!, as escadeiras, Ui!, as pernas, Ai!, Ui!, sem posição, Alá, vovó, alá as luzes de São o filho esperando Tantos anos! Ganhar a vida em Sampaulo, no Brejo Velho Duas vezes só, voltou, meu Deus, isso em solteiro, depois, apenas os retratos carreavam notícias, o emprego, a namorada-agoraesposa, eles dois, a casa descostelada, os netos, e vamos então esperar a senhora para passar o Dia das Mães com nossa família e todos vamos ficar muito felizes não preocupa não que eu vou buscar a senhora na rodoviária lembranças a todos do a bexiga caxumbenta, o intestino goguento... ${ }^{1}$

1 RUFFATO, Luiz. Eles eram muitos cavalos. São Paulo: Boitempo, 2001. p. 16-17 
Nesse excerto, transcrito com todos os grifos a partir do original, podemos identificar a inserção do trecho de uma carta, que está destacado em itálico e escrito em letra menor. A troca de gêneros textuais em um romance não é novidade. Mas o modo como isso se dá no trecho acima é significativo.

Segundo Reuter, os gêneros "limitam as narrativas, primeiro impondo modos de organização, mais ou menos rígidos, à diversidade seqüencial e, em seguida, comandando formas mais ou menos codificadas para essas seqüências.”2 Vejamos, então, como estas seqüências estão organizadas no fragmento citado.

Em uma leitura rápida, podemos identificar quatro variações no mesmo tipo de letra. Se isolarmos o que está em itálico e o que está em negrito, teremos uma seqüência dialogal, que, para Reuter, é "caracterizada pelo encadeamento de réplicas sob a forma de afirmações ou de perguntas-respostas". ${ }^{3}$ Neste caso, um diálogo entre a velha senhora e o motorista do ônibus. O trecho da carta é uma seqüência argumentativa, em que o filho tenta convencer a mãe a fazer a viagem, isto é, defende uma determinada tese "por meio de argumentos, concessões". ${ }^{4}$ Há ainda uma seqüência descritiva, "a bexiga estufada, dói a barriga, as costas, (...) as escadeiras, (...) as pernas, (...) sem posição (...) a bexiga caxumbenta, o intestino goguento(...)", que corresponde à voz do narrador, de quem falaremos daqui a pouco.

Sobre o modo de inserção das seqüências na narrativa, Reuter diz que elas podem

romper de maneira clara o curso da narração ou, pelo menos, distingui-lo claramente: a inserção de uma carta ou de uma notícia de jornal (...) Em compensação, ela pode tender a fundir-se na narração que apaga o máximo possível os signos demarcativos. (...) Um dos meios para realizar tal apagamento consiste em delegar o controle dessas seqüências às personagens (e não mais ao narrador), que dialogam, explicam e argumentam entre si. Elas aparecem, pois, como produto das atividades dos protagonistas. $^{5}$

2 REUTER, Yves. A análise da narrativa: o texto, a ficção e a narração. Rio de Janeiro: Bertrand Brasil, 2002. p. 130.

3 Ibid., p. 128.

4 Id.

5 Ibid., p. 146. 
Pela leitura do fragmento acima, já podemos sublinhar dois aspectos relevantes para o andamento desta análise. O primeiro é que o rompimento se dá de forma clara e marcada quando consideramos a inserção das seqüências e a variação de gêneros entre o conjunto de textos que formam o romance, como vimos no início e ilustramos ainda com um trecho do anúncio de jornal que corresponde ao capítulo 42:

\footnotetext{
CLAUDINEI - Moreno, 33 anos, $1,71 \mathrm{~m}, 74 \mathrm{Kg}$, cabelos e olhos castanhos. Motorista. Deseja se corresponder com loira de 18 a 30 anos para compromisso sério. Pede carta com foto ou telefone. (...)

SOZINHO - Homem branco, 34 anos, 1,65 m, $62 \mathrm{Kg}$, cabelos pretos, olhos castanhos, comerciante. Deseja se corresponder com moça branca, baixinha, carinhosa e sem vícios. ${ }^{6}$
}

A outra é que as seqüências narrativas do excerto estudado acima (e de boa parte do livro), embora estejam submetidas ao controle das personagens (o que seria uma forma de apagar os signos demarcativos), rompem claramente o curso da narração, na medida em que se intercalam e se sobrepõem, sem critério de organização aparente, e que são formadas por frases destacadas por recursos gráficos.

Portanto, com a diversidade de gêneros narrativos, que é marcante tanto num mesmo capítulo, quanto entre os capítulos do romance, a sobreposição e intercalação das seqüências narrativas e o destaque entre as frases, podemos ilustrar como a idéia de diversidade está representada em quatro níveis da dimensão formal do romance. Como veremos em seguida, esta forma ganha em significado quando a interpretamos em paridade com o conteúdo. Para isso, veremos como se comportam alguns dos narradores do romance.

O narrador do capítulo 6 é heterodiegético, com perspectiva passando pelo narrador. Ele se situa fora do enredo, mas tem acesso ao íntimo da velha senhora que viaja no ônibus. Este narrador indica, pelo "Garanhuns - São Paulo", pelo "Ganhar a vida em Sampaulo" e pelo "Duas vezes só, voltou, meu Deus", que o assunto do fragmento é a migração nordestina.

Pela sobreposição de seqüências e pela variedade nos registros gráficos, o narrador demonstra o desconforto da personagem - os pensamentos, as falas, as

6 RUFFATO, op. cit., p. 90-91. 
dores, tudo se intercala gerando uma certa tensão na narrativa. Uma tensão inerente ao ponto de vista de quem vê a metrópole de fora, de quem é estranho àquele mundo que se aproxima:

...E gente inda consegue dormir, meu Deus, a bocona jacaroa, até ronca!, até baba!, comé que?, embaralham-se distintas paisagens, cidades enoooormes, cidadezinha que, zum!, passou, (...) o mundo, o mundogrande, que não se acaba mais nunca..."”

É neste mundogrande que está seu filho; distante de seu mundo de origem. Para a mãe, estes dois mundos são incompatíveis. Podemos, então, dizer que a segmentação na forma representa esta incompatibilidade.

No fragmento 41, o migrante reaparece. Desta vez, através de um narrador homodiegético, com perspectiva passando pelo narrador, na pele de um motorista de táxi. O narrador abre o relato dirigindo-se ao passageiro que acaba de entrar no táxi:

O doutor tem algum itinerário de preferência? Não? Então vamos pelo caminho mais rápido. Que não é o mais curto, o senhor sabe. Aqui em São Paulo nem sempre o caminho mais curto é o mais rápido. ${ }^{8}$

O que segue, a partir de então, é um monólogo (que tem o passageiro como interlocutor que não se pronuncia) que se estende por 7 páginas, escritas em um único parágrafo. Claudionor, o motorista, conta sua vida "pelo caminho mais rápido", isto é, intercala os assuntos em ritmo semelhante a um fluxo de consciência (e de trânsito):

Sabe que uma vez eu sonhei que a cidade parou? Parou mesmo, totalmente. Um engarrafamento imenso, um congestionamentomonstro, como nunca antes visto, e ninguém conseguia andar um centímetro que fosse... Parece coisa de cinema, não é não?

7 Ibid., p. 16-17.

8 Ibid., p. 84. 
Pois eu gosto. Gosto muito de assistir filme. Mas prefiro os antigos. De vez em quando reprisa um na televisão. Tinha uns atores danados de bons Tyrone Power, Burt Lancaster...(... $)^{9}$

O narração ainda segue sobre diversos temas, que variam conforme a vontade do narrador, por associação livre. Claudionor, então, fala de sua família. Ele a divide em duas gerações, a que nasceu na época em que ele estava melhor financeiramente e a que foi vítima de sua falência:

Mas lá em casa tem duas gerações, uma, a das meninas mais velhas, a Maria Perpétua e a Maria do Carmo, que pegaram a fase mais boa, estudaram, se formaram, a Maria do Carmo é até doutora-advogada, tem escritório, junto com um sócio, lá no Horto, é solteira, está bem de vida, tem um ótimo apartamento lá por perto mesmo, já foi pro estrangeiro, o senhor acredita? (...) A Maria Perpétua formou pra professora, casou, mora no Campo Limpo, dá aula numa escola municipal, está bem de vida, graças a deus, o marido é negociante, gente boa, meio malandrão, mas nesse meio de berganha quem não é vivo não tem futuro, o senhor não concorda?, tem que ser. ${ }^{10}$

Neste primeiro grupo, podemos notar que, de um lado, está a filha "doutoraadvogada"; do outro, o genro negociante e "meio malandrão". Este malandro é diferente daquele apontado por Antonio Candido, no ensaio "Dialética da Malandragem"(1970). ${ }^{11}$ Lá, o malandro "pratica a astúcia pela astúcia (...) manifestando um amor pelo jogo-em-si", isto é, sem causar dano a ninguém. Aqui, o genro negociante, embora esteja sumariamente descrito, se aproxima mais do pícaro, que, conforme Candido, "visa quase sempre ao proveito ou a um problema concreto, lesando freqüentemente terceiros na sua solução", como sugere a afirmação "nesse meio de berganha quem não é vivo não tem futuro, o senhor não concorda?, tem que ser." Assim, dentro deste primeiro grupo temos dois extremos: quem representa a lei e quem a transgride. Vejamos o outro grupo:

9 Id.

10 Ibid., p. 89.

11 CANDIDO, Antonio. Dialética da malandragem. In: Duas Cidades, 1992. . O discurso e a cidade. São Paulo: 
Mas os outros dois filhos pegaram a fase ruim, a Maria Lúcia e o Pedro já não foram tão longe assim nos estudos... Mas graças a deus isso não obstaculou que ficassem bem. A Maria Lúcia é a mulher do meu genro que tem casa na Praia Grande, ela é do lar, estudou até o ginasial, mas tá até melhor de vida que as irmãs. O Pedro tem uma barraquinha de feira, vende banana, o senhor sabe que isso de vender banana na feira é até um bom negócio? O Pedro está bem. ${ }^{12}$

Este trecho revela a ponta de baixo da escala social da família. Ao compararmos esta à primeira geração, percebemos um abismo social entre a irmã advogada e o irmão feirante. Portanto, há também a referência a dois mundos distintos e incompatíveis, agora no interior da estrutura familiar.

Claudionor, então, fala de si mesmo:

Saí de casa muito cedo, menino ainda. Desci do norte de paude-arara. Se o senhor soubesse o que era aquilo... Um caminhão velho, lonado, umas tábuas atravessadas na carroceira, servindo de assento, a matula no bornal, rapadura e farinha, dias e dias de viagem, meu deus do céu! $!^{13}$

Esta imagem é marcante no retrato da migração nordestina não só na literatura. Neste trabalho, ela é paralela à imagem que o outro narrador nos passa da velha senhora no ônibus. Mas, neste caso, o relato é de um ponto de vista inverso, ou seja, de um homem já acostumado à metrópole, um homem para quem o desconforto da viagem valeu a pena:

Mas posso reclamar não. São Paulo, uma mãe pra mim. Logo que cheguei arrumei serviço, fui trabalhar de faxineiro numa autopeças em Santo André. Depois fui subindo de vida, porque aqui antigamente era assim, quem gostasse de trabalhar tinha tudo, ao contrário de hoje, que não tem emprego pra ninguém. ${ }^{14}$

12 RUFFATO, op. cit., p. 89-90.

13 Ibid., p. 87.

14 Id. 
No entanto, a adaptação de Claudionor a um mundo diferente do seu não o afasta da possibilidade de promover um choque entre esses dois mundos. Isso acontece quando a personagem leva a família para conhecer sua terra natal:

Uma vez levei a família inteira, seis enfiados num fuscão zerinho que tinha acabado de comprar. (...) um pandemônio, êta viagem empesteada! As meninas nunca mais voltaram lá... Eu fico triste, não vou mentir pro senhor não. Afinal, é a terra da gente. Mas eu entendo. Não sou ignorante não. Elas não têm nada a ver com aquele buraco lá. Pra falar a verdade, nem eu tenho mais a ver com aquilo. A maioria dos meus colegas de infância, do pessoal que eu conhecia, não mora mais lá. Os velhos morreram todos. A única coisa que resta é a memória da gente, mas o que é a memória da gente? ${ }^{15}$

O menino que saiu de casa em um caminhão "pau-de-arara", agora volta pai de família em um "fuscão zerinho". Sua ascensão na escala social, a reação negativa da família e, principalmente, a perda de seus referenciais manifestada pela relativização do valor das suas memórias, fazem com que ele próprio já não reconheça como seu o mundo de onde saiu. Este sentimento de incompatibilidade, que o separa de suas origens, nos aproxima, mais uma vez, da idéia de ruptura.

Dessa forma, o motorista de táxi Claudionor pergunta e responde qual o itinerário prefere para fazer o relato de sua vida. A idéia de diversidade está desdobrada na incompatibilidade e ruptura presente tanto na forma da sua narrativa, como em sua família e nele mesmo.

Na dimensão formal de sua narrativa, ecoa a idéia de diversidade que permeia todo o romance. $\mathrm{O}$ andamento é marcado pela associação livre de idéias, que faz com que seu interlocutor ouça desde relatos de foro íntimo sobre sua família, à sua opinião sobre filmes pornográficos. A ruptura constante entre os temas se relaciona à sobreposição e intercalação de seqüências narrativas, que vimos anteriormente.

$\mathrm{Na}$ esfera da família, há divergências de extensão ética e social. Explorando um pouco mais o discurso da personagem, é possível decodificar algumas idéias que podem ser representativas no cotidiano, tanto dos grandes centros urbanos, como da sociedade brasileira como um todo. 
Quando fala de Pedro, que nasceu e cresceu no período da sua crise financeira, Claudionor diz que o filho está bem, que "vender banana na feira é até um bom negócio". Este pode ser o discurso de um pai que quer pintar a melhor imagem de seus filhos. Mas, ao mesmo tempo, pode ser o de um cidadão já acostumado a presenciar a desigualdade social em seu contexto.

Na passagem em que fala sobre a primeira geração da família, aquela que teria sido beneficiada por sua situação financeira, Claudionor coloca, lado a lado, a filha advogada e o genro contraventor. Não há constrangimento em seu discurso, afinal, segundo ele, "quem não é vivo não tem futuro". Sob o ponto de vista do cidadão comum da grande cidade, pode ser até uma questão de sobrevivência. Mas para Claudionor, o migrante nordestino, isso representa um aprendizado.

Este é o ponto em que devemos verificar se esta leitura pode entender este livro como um romance. Para tanto, vejamos como esta personagem reage com alguns aspectos inerentes à forma. No ensaio "O pobre diabo no romance brasileiro", José Paulo Paes apresenta uma leitura esclarecedora de alguns pontos da teoria de Georg Lukács. Segundo ele, Lukács anota que o romance passa a existir quando a incoerência estrutural do mundo ameaça a forma artística e o próprio indivíduo se problematiza. Este indivíduo, o herói problemático, quando presente no "romance de formação", mostra-se "buscando, nas suas peregrinações pelo mundo da realidade social, um jeito de com ele conciliar os ideais que traz dentro de si, mas sem traílos." ${ }^{16}$ Quando este herói atua no "romance da desilusão", aparece como alguém que, após o fracasso de seus ideais, desiste de qualquer forma de conciliação, só lhe restando "de um lado, o acomodamento com a sociedade por via da aceitação resignada de suas formas de vida, por outro lado, o recuo sobre si mesmo e a conservação em si de uma interioridade que só se pode realizar na alma." ${ }^{\prime 7}$

A simbólica passagem da viagem de Claudionor à sua terra representa um momento decisivo em sua vida: a ruptura com seus referenciais de origem. Daí em diante, Claudionor pode passar a ser visto como um indivíduo sem "uma essência definida, pronta para atualizar; esta irá se constituindo ao longo do processo histórico da existência dele." Ora, se Claudionor pode ser visto como um indivíduo cuja essência está se construindo ao longo de sua existência, ele nem tenta conciliar seus ideais com o mundo da realidade social, tampouco conserva em si uma interioridade que se realiza na alma. Das duas definições de herói, ele se aproxima da segunda, mas somente na medida em que aceita as formas de vida da sociedade. Claudionor,

16 PAES, José Paulo. O pobre diabo no romance brasileiro. In: A aventura literária: ensaio sobre ficção e ficções. São Paulo: Companhia das Letras, 1990. p. 55.

17 Ibid., apud LUKÁCS, Georg, p. 56. 
nesses termos, não tem vocação para herói. Mas pode ser interpretado como um indivíduo que, como vimos, reavalia seus valores enquanto percorre uma trajetória em busca da (re)construção de sua essência.

Sob esse ponto de vista, a fragmentação na forma de narrar, a incompatibilidade entre os temas, a apatia diante da desigualdade ética e social presente na família seria resultado desse processo de reconstrução. Sendo assim, Claudionor materializa sua subjetividade na forma. Quando fala de si mesmo, ele revela um dos tantos anônimos que habitam São Paulo e este romance. Ele tanto pode ser a velha senhora que viaja no ônibus, como o "Claudinei" ou o "Sozinho" do anúncio de jornal. Como migrante nordestino que vive naquela cidade, ele está entre aqueles milhares de indivíduos cuja experiência de vida é marcada por um processo de adaptação a um novo mundo. Como personagem deste romance, além de mais um na galeria de tipos humanos composta pelos narradores, Claudionor é a metáfora da forma dessas narrativas, na medida em que sua trajetória no processo de reconstrução de sua essência se assemelha à trajetória do leitor, que mesmo diante da diversidade formal e temática desse conjuntos de textos, pode entendêlos como a um romance.

Esta é uma das leituras possíveis desse universo que Luiz Ruffato decalca na cidade de São Paulo. A escolha da figura do migrante nordestino, além de ter sido motivada pela razão óbvia de que milhares deles vivem na cidade, foi favorecida pelo modo peculiar com que é representada no romance. Mas, ao mesmo tempo, temos a impressão de que a diversidade da dimensão humana da cidade pode ser investigada a partir de qualquer um dos capítulos e dos personagens do livro. Se isso de fato for possível, com Eles eram muitos Cavalos, Ruffato abre espaço na linhagem de autores da Literatura Brasileira que apresentam soluções relevantes para a evolução do tratamento do homem comum, especialmente o confinado nos grandes centros urbanos: os "muitos cavalos" de Cecília Meireles, aqueles que ninguém mais sabe seus nomes, sua pelagem, sua origem. 


\section{RESUMO}

Este artigo pretende apresentar um proposta de leitura para Eles eram muitos cavalos, de Luiz Ruffato, com base em dois capítulos que têm como pano de fundo a migração nordestina para São Paulo. Através do estudo da figura do migrante, sobretudo de seu processo de adaptação a um contexto diferente ao seu de origem, pretende-se alcançar a representação da diversidade formal e humana no todo da obra. A análise começa com algumas considerações sobre os aspectos formais relevantes para a proposta e, em seguida os interpreta em paridade com o conteúdo.

Palavras-chave: Literatura brasileira, sociologia da literatura, literatura e sociedade.

\section{ABSTRACT}

This article intends to present a purpose to the reading of Eles eram muitos cavalos, by Luiz Ruffato, based on two chapters in which background is northeastern migration to São Paulo. Through the study of migrant, mainly of its process of adaptation in a different context, it intends to reach the formal and human diversity in the whole novel. The analysis begins with some considerations about formal aspects that are relevant to the purpose and then interprets them in equality to the content.

Key-words: Brazilian literature, sociology of literature, literature and society.

\section{REFERÊNCIAS}

CANDIDO, Antonio. Dialética da Malandragem. In: O discurso e a cidade. São Paulo: Duas Cidades, 1992.

PAES, José Paulo. O pobre diabo no romance brasileiro. In: . A aventura literária : ensaio sobre ficção e ficções. São Paulo: Companhia das Letras, 1990.

REUTER, Yves. A análise da narrativa: o texto, a ficção e a narração. Rio de Janeiro: Bertrand Brasil, 2002.

RUFFATO, Luiz. Eles eram muitos cavalos. São Paulo: Boitempo, 2001. 